\title{
Percepção dos estudantes do ensino fundamental sobre a educação financeira e o consumo consciente
} Elementary students' perception on financial education and conscious consumption

\section{Percepción de los estudiantes de la enseñanza \\ fundamental sobre la educación financiera y el consumo consciente}

\author{
Alexandre Costa Quintana \\ Universidade Federal do Rio Grande (FURG), Rio Grande/RS - Brasil \\ Katiani Velleda Pacheco \\ Universidade Federal do Rio Grande (FURG), Rio Grande/RS - Brasil
}

\begin{abstract}
Resumo
O presente trabalho tem por objetivo verificar a percepção dos estudantes do ensino fundamental sobre a educação financeira e seu uso no planejamento do orçamento familiar. Esse tema foi escolhido a partir da criação de um projeto de extensão, desenvolvido por professores e estudantes do curso de ciências contábeis, em uma universidade pública do Rio Grande do Sul, que aborda a educação financeira para jovens do ensino fundamental. A pesquisa foi desenvolvida com 55 alunos dessa etapa. Por meio da aplicação de um questionário, gerou-se uma interpretação quantitativa e qualitativa das respostas. Conclui-se que, em se tratando de aquisição de habilidades financeiras, os alunos não se encontram preparados para as tomadas de decisões necessárias para uma vida financeira controlada e segura. Eles precisam adquirir informações sobre finanças não somente no âmbito familiar, mas em outros ambientes que possam auxiliá-los de forma eficaz nessas decisões. Ainda há poucas iniciativas por parte do Ministério da Educação (MEC), para incluir, no currículo escolar, conceitos e informações financeiras aos alunos, salvo algumas exceções, conhecidas durante a pesquisa.
\end{abstract}

Palavras-chave: Orçamento familiar, Renda, Gastos, Educação financeira

\begin{abstract}
The purpose of this study is to verify the perception of elementary school students about financial education and its use in family budget planning. This theme was chosen from the creation of an extension project, developed by professors and students of the Accounting Sciences course at a public university of Rio Grande do Sul, which deals with financial education for young people in elementary education. The research was developed with 55 elementary students, who have answered a questionnaire, generating a quantitative and qualitative interpretation of the answers. It is concluded that when it comes to acquiring financial skills, students are not
\end{abstract}


prepared to take the necessary decisions for a controlled and secure financial life, needing to acquire information about finances not only in the family, but in other environments that can assist them effectively in these decisions. There are still few initiatives by the Brazilian Ministry of Education (MEC) to include concepts and financial information to the students in the school curriculum, except for some exceptions that could be known during the research.

Keywords: Family budget; Income; Spending; Financial education.

\section{Resumen}

El presente trabajo tiene por objetivo verificar la percepción de los estudiantes de la enseñanza fundamental sobre la educación financiera y su uso en la planificación del presupuesto familiar. Este tema fue elegido a partir de la creación de un proyecto de extensión, desarrollado por profesores y estudiantes del curso de Ciencias Contables en una Universidad Pública de Rio Grande do Sul, que aborda la educación financiera para jóvenes de la enseñanza fundamental. La investigación fue desarrollada con 55 alumnos de la enseñanza fundamental, a través de la aplicación de un cuestionario, generando una interpretación cuantitativa y cualitativa de las respuestas. Se concluye que, en lo que se refiere a la adquisición de habilidades financieras, se observa que los alumnos no se encuentran preparados para tomar las decisiones necesarias para una vida financiera controlada y segura, necesitando adquirir información sobre las finanzas no sólo en el ámbito familiar, sino también otros entornos que puedan ayudarlos eficazmente en estas decisiones. Aún hay pocas iniciativas por parte del Ministerio de Educación y Cultura (MEC) de incluir en el currículo escolar conceptos e informaciones financieras a los alumnos, salvo algunas excepciones que se pudieron conocer durante la investigación.

Palabras clave: Presupuesto familiar, Ingresos, Gastos, Educación financiera

\section{Introdução}

Com base em estudos realizados por Savoia, Saito e Santana (2007), Grando e Schneider (2011) e Trevisan et al. (2007), pode-se observar que a educação financeira está cada vez mais presente nos debates, contribuindo para uma melhor compreensão sobre o tema. No entanto, percebe-se que as famílias não possuem as informações necessárias para uma vida financeira saudável. Embora a discussão sobre essa temática esteja aumentando no Brasil, ainda se percebe que há poucas informações sobre educação financeira, e que esses conceitos poderiam ser transmitidos também no ambiente escolar, para melhor auxiliar a sua compreensão pelos estudantes. Conforme Vieira, Bataglia e Sereia (2011), países como Estados Unidos e Reino Unido já ofertam disciplinas sobre educação financeira em escolas de ensino médio, e, mesmo sendo disciplinas optativas, a procura é muito grande. 
Conforme estudo realizado por Savoia, Saito e Santana (2007), no Brasil, existem algumas iniciativas de projetos desenvolvidos por órgãos governamentais, instituições financeiras e de ensino, tais como o Ministério da Educação (MEC), que sugere a inserção de conteúdos multidisciplinares; o Banco Central do Brasil (Bacen) com o Programa de Educação Financeira (PEF) - fazem parte desse programa o Projeto Museu-Escola, Projeto o Museu vai à Escola, Projeto BC e Universidade; Comissões de Valores Mobiliários (CVM) e Bolsa de Valores de São Paulo (Bovespa), com os projetos Educar e Bovespa vai até você; Federação Brasileira de Bancos (Febraban), Serasa, Associação Nacional dos Bancos de Investimento (Anbid) e Banco Itaú. Entretanto, esses ainda não são suficientes para garantir o acesso a informações sobre educação financeira a todos os adultos.

Em conformidade com o exposto acima, nasce a necessidade de que o tema seja debatido em sala de aula. Bussinger (2005) afirma que 90\% das pessoas aprendem a lidar com dinheiro através dos seus pais. Considerando que a maioria dos sujeitos estuda, a escola seria o espaço de aprender sobre como lidar com suas finanças, pois somente os familiares não conseguem transmitir a seus filhos todos os conhecimentos necessários a uma vida financeira sustentável. De acordo com as contribuições de Trevisan et al. (2007, p. 2) "dessa forma, uma das lacunas existentes no sistema educacional brasileiro seria a ausência da aprendizagem de noções de finanças nas escolas, especialmente no ensino médio, o qual para muitos antecede a entrada no mercado de trabalho". Assim sendo, seria necessário que as famílias e a escola buscassem procedimentos básicos para auxiliar os jovens a compreender a importância de administrar suas finanças conscientemente, ajudando-os a se tornarem adultos responsáveis financeiramente. Savoia, Saito, Santana (2007) complementam que a educação financeira é uma forma de adquirir conhecimentos que auxiliam nas decisões relacionadas às finanças, tanto pessoais como em tomada de decisões.

Diante do exposto, o presente trabalho tem como objetivo descrever a percepção dos estudantes do ensino fundamental sobre a educação financeira e seu uso no planejamento do orçamento familiar. Os objetivos específicos são: verificar o grau de instrução dos alunos do ensino fundamental em relação ao uso de seu dinheiro, avaliar as atitudes dos alunos em relação as suas finanças pessoais e avaliar a importância da educação financeira para seu futuro. 
Esse tema foi escolhido a partir da criação de um projeto de extensão, desenvolvido por professores e estudantes do curso de ciências contábeis em uma universidade pública do Rio Grande do Sul, que aborda a educação financeira para alunos do ensino fundamental, no qual se percebe que o tema é pouco desenvolvido. Nesse sentido, há necessidade de explorá-lo mais, proporcionando a esses jovens uma melhor compreensão sobre o orçamento de suas famílias. $O$ projeto é relevante, visto a necessidade de todos aprenderem e desenvolverem as habilidades necessárias para lidar com suas finanças de forma consciente.

A partir dessas informações, as famílias poderão programar e organizar melhor seu orçamento, possibilitando uma estrutura financeira de melhor qualidade, podendo, assim, até mesmo reduzir o consumismo, por ser esse um dos grandes problemas da falta de estrutura financeira. Dessa forma, evitam-se problemas como inadimplência, endividamento e falta de recursos para o futuro. Essa mudança não ocorre de forma instantânea, por ser um processo de longo prazo, em que os indivíduos e as famílias vão se familiarizando com os novos costumes e aprendendo cada dia sobre a nova forma de gerir suas finanças pessoais.

O presente estudo está dividido em cinco seções. A primeira é a introdução, em que se define o contexto do estudo e o objetivo da pesquisa. Na segunda, é apresentado o referencial teórico, trazendo as informações de pesquisas realizadas por vários autores nessa área. $\mathrm{Na}$ sequência, são definidos os aspectos metodológicos, ou seja, a forma como o trabalho foi desenvolvido. A seção quatro apresenta a percepção dos estudantes sobre a importância da educação financeira, os dados da pesquisa e a sua análise. Na seção cinco, são apresentadas as considerações finais do estudo.

\section{Referencial teórico}

O referencial teórico está estruturado visando a mostrar como se apresentam, em termos de literatura, os dois tópicos principais que abrangem o foco do presente estudo: a educação financeira e o consumismo. A educação financeira como forma de estudo para aquisição de habilidades financeiras, capazes de proporcionar uma melhor qualidade de vida às famílias, aprender a economizar e controlar seus gastos de forma correta, e o consumismo como forma de consumir somente o necessário, deixando as falsas necessidades de lado. 


\subsection{Educação financeira}

De acordo com Cerbasi (2012), a partir dos conhecimentos adquiridos com a educação financeira, os sujeitos passam a ter controle sobre seu dinheiro, além de controlar o uso de sua renda e de planejar de forma adequada suas escolhas.

A educação financeira, como processo de aprendizagem, busca desenvolver as habilidades necessárias aos indivíduos, para que possam gerir suas finanças de forma adequada, evitando assim o endividamento, o consumo desnecessário, a falta de reservas em longo prazo, assim como uma possível forma de garantir uma vida mais saudável e segura. Sendo assim, para Borges (1999), a educação financeira surge como uma ferramenta de inclusão social, de melhoria de vida do cidadão e de promoção da estabilidade, da concorrência e da eficiência do sistema financeiro do país.

Conforme Souza, Silva e Queiroz (2013), a falta de conhecimentos a respeito do planejamento financeiro vem trazendo resultados negativos para as famílias, como falha em seus compromissos financeiros, dificuldades em realizar seus objetivos pessoais, causando, assim, a desestabilidade no ambiente familiar e, possivelmente, piorando a qualidade de vida dessa família. Ainda segundo os autores, a pesquisa realizada pela Confederação Nacional do Comércio (CNC), relacionada à inadimplência e ao endividamento do consumidor, indicou que essa relação chegou ao patamar de 59,8\%, em agosto de 2012.

Para Cerbasi (2012), os filhos devem fazer parte da elaboração do orçamento familiar, não necessariamente em sua íntegra, mas em partes que envolvam sua "mesada", viagens e festas de família, para que já possam ter noção de educação financeira para o futuro. A reunião familiar na decisão de como será gasto o orçamento familiar pode ser uma alternativa para aprender a gastar com consciência, mesmo que em pequena escala. Conforme Lellis, Magalhães e Leite (2011), a mesada é o dinheiro que os pais dão aos filhos, sendo uma forma que os pais encontraram para inserir seus filhos no mundo econômico, auxiliando-os na compreensão dos conceitos relacionados a finanças e buscando torná-los adultos responsáveis economicamente no futuro.

Segundo Santomé (1998), o currículo escolar era organizado de forma cultural, afastando-se da realidade vivida pelos cidadãos, não contemplando seu 
objetivo principal de educar para a vida. O autor acrescenta que já existem muitas leis que admitem um currículo que vise à integração de conteúdos, propondo aos estudantes melhor entendimento de situações e práticas vivenciadas em seu dia a dia, com destaque para a Lei de Diretrizes e Bases da Educação - LDB (Lei 9.394/96), que, em seus artigos 22 e 32, menciona:

Art. 22. A educação básica tem por finalidade desenvolver o educando, assegurarIhe a formação comum indispensável para o exercício da cidadania e fornecer-lhe meios para progredir no trabalho e em estudos posteriores. Art. 32. O ensino fundamental obrigatório, com duração de 9 (nove) anos, gratuito na escola pública, iniciando-se aos 6 (seis) anos de idade, terá por objetivo a formação básica do cidadão, mediante: II - a compreensão do ambiente natural e social, do sistema político, da tecnologia, das artes e dos valores em que se fundamenta a sociedade; III - o desenvolvimento da capacidade de aprendizagem, tendo em vista a aquisição de conhecimentos e habilidades e a formação de atitudes e valores.

Para Mello (2000), um dos motivos de não haver disciplinas que discutam a educação financeira nas escolas pode estar na má formação dos professores, posto que os cursos superiores estejam com seu currículo um tanto antiquado e não possibilitam aos profissionais uma preparação para despertar nos alunos as habilidades necessárias, por meio de disciplinas específicas que abordem a educação financeira. Dessa forma, na visão de Trevisan et al. (2007), com a rápida evolução que vem ocorrendo na sociedade, são necessárias informações que as acompanhem, além de uma constante formação dos professores, para que sejam ministradas aulas em que os alunos desenvolvam as habilidades de consciência, autonomia e reflexão.

Ainda conforme Brasil (2002, p. 23), "as transformações científicas e tecnológicas que ocorrem de forma acelerada exigem das pessoas novas aprendizagens. Esse contexto coloca enormes desafios para a sociedade e também para a educação escolar". A respeito disso, é relevante o exposto, que destaca a formação continuada como uma necessidade dos profissionais da educação escolar. Nesse sentido, ao serem educadas financeiramente no ambiente escolar, as crianças estarão adquirindo conhecimentos necessários para permitir uma vida financeira saudável, de forma a auxiliá-las, tanto sob o aspecto pessoal como profissional.

Conforme Savoia, Saito e Santana (2007), não há uma obrigação na inserção do ensino de educação financeira no sistema escolar no Brasil. O MEC apenas exige um ensino interdisciplinar, que faça com que os estudantes tenham Revista Educação Online, Rio de Janeiro, n. 27, jan-abr 2018, p. 130-150 
capacidade de desenvolver habilidades necessárias para lidar com situações tanto pessoais, quanto sociais em sua vida. Nessa perspectiva, percebe-se que os conhecimentos sobre educação financeira deveriam ser ensinados de forma explícita, em que os alunos pudessem refletir sobre esses ensinamentos de maneira prática, não se utilizando de modelos tão universais como se percebe na atualidade.

Além disso, segundo Peter e Palmeira (2013), a partir da introdução da educação financeira nos currículos escolares iniciais, os estudantes de hoje, ou seja, os profissionais do futuro, agregam conhecimentos e informações para lidar com os desafios no mercado de trabalho, contribuindo com o crescimento do país. Para Kiyosaki e Lechter (2000), o dinheiro sem educação financeira é um dinheiro que some rápido, por falta de consciência na hora de gastá-lo. O importante não está em quanto dinheiro se ganha, mas sim em quanto você consegue poupar.

A partir do exposto, entende-se que o objetivo da educação financeira é ensinar as pessoas a gerir suas finanças, obtendo noções relacionadas ao dinheiro, tais como orçamento, poupança, empréstimos, entre outros. Através do investimento em educação financeira, será possível auxiliar as pessoas a definir metas financeiras e apurar suas finanças. Portanto, estando preparadas para administrar suas finanças pessoais, evita-se que sejam induzidas ao consumismo desenfreado e o seu consequente endividamento pessoal.

\subsection{Consumismo}

O consumismo pode ser um dos problemas derivados da falta de estrutura financeira, pois faz com que os gastos sejam além dos ganhos, promovendo, assim, um desequilíbrio financeiro, que acaba por ocasionar problemas como a inadimplência, a falta de reservas para eventuais problemas futuros, entre outros. Para Barbosa (2010), o consumo de objetos, somente porque o outro possui, ou como status social, ou ainda como fator de diferenciação de classes e exclusão social, estão em sua plenitude.

De acordo com Silva (2014), o consumismo pode ser dividido em duas partes; o ser, indivíduo que demonstra a capacidade de consumir com responsabilidade, o que se preocupa com o próximo, aquele que consome o necessário, não se deixando levar por vontades ou status social; e o ter, que nos remete a um egoísmo, a consumir, mesmo que não seja necessário, somente para possuir o objeto, para 
satisfação pessoal, sem necessidade, o qual deriva de uma sociedade consumista ou de produtos.

Ainda conforme esse autor, quando o consumo acontece de forma desnecessária ou em busca de status social, ele acaba por transformar os consumidores em mercadorias a serem consumidas por outras pessoas, perdendo assim sua capacidade de serem agentes ativos do consumo e se transformando em um consumidor que somente está preocupado em possuir o objeto. Para Bauman (2008), a principal característica da sociedade de consumo é a transformação dos consumidores na própria mercadoria. Portanto, o principal objetivo do consumidor é saber distinguir as coisas imateriais, focando suas necessidades principais.

Conforme Viera, Bataglia e Sereia (2011), até mesmo as decisões financeiras particulares podem influenciar na economia em geral, atreladas a questões como a inadimplência, o endividamento das famílias e a falta de capacidade de planejar para o futuro. Essas decisões de consumo e gastos não planejados acabam por prejudicar não só a vida financeira das famílias, mas sim de todo um país.

Para Borges (1999, p. 26), "há pais que compram tudo que a criança quer e muito mais", devido à falta de tempo para estarem com seus filhos. Pelo fato de os pais estarem trabalhando mais, em busca de uma renda maior, eles trocam a falta de carinho por coisas, fato que pode ser um causador do desequilíbrio no orçamento das famílias. Torna-se necessário um controle, não os acostumar a ganhar tudo que querem, pois, muitas vezes, querem objetos de que não têm nenhuma necessidade em possuí-lo. Ainda sobre Borges (1999), as crianças se tornam consumidores passivos assim que nascem e, conforme seu crescimento, vão formando sua personalidade, quando acabam por decidir sozinhos o que comprar, mesmo sem saber para quê.

Uma forma de auxiliar as crianças a não crescerem com uma visão distorcida sobre a realidade financeira de seus pais é mostrar que existe todo um trabalho para que se possa ter dinheiro.

Segundo o Instituto Nacional de Metrologia, Qualidade e Tecnologia (Inmetro) (2002, p. 18), "um especialista em marketing para criança afirmou: mesmo crianças com dois anos de idade estão interessadas na marca de suas roupas, e aos seis anos já são consumidores formados". Além disso, conforme pesquisa do Inmetro (2002), as crianças brasileiras de até 14 anos de idade atingem cerca de $40 \%$ da 
população, dessa forma, as empresas ampliam suas estratégias de venda para seção infantil, principalmente, no segmento de brinquedos.

De acordo com Braustein e Welch (2002), os consumidores podem ser facilmente influenciados pelas propagandas de marketing, consumindo, dessa maneira, produtos que não condizem com sua necessidade ou com seu orçamento. Por meio do estudo do comportamento humano, em conformidade com Silva (2014), os publicitários não pretendem passar aos consumidores somente a qualidade do produto, mas o status e a identidade social que eles podem alcançar se o possuírem.

Conforme o Inmetro (2002), o objetivo das propagandas é fazer com que os consumidores se sintam incompletos, insatisfeitos, imperfeitos, incentivando-o a comprar seu produto, mesmo que não ele seja necessário. Sendo assim, o consumidor, ao adquirir tal objeto, tem a sensação de se tornar completo, bonito e aceito pela sociedade. Para Carvalho (2000), o princípio da publicidade é a indústria dos sonhos distantes da vida real, mostrando aos consumidores uma visão distorcida da sociedade, até mesmo mantendo conceitos ultrapassados que, por ventura, já não cabem mais nos tempos atuais.

Dessa forma, para que se possa adquirir as habilidades necessárias a um consumo consciente, é fundamental que se tenha um ensino adequado, com profissionais habilitados na área da educação, que possam auxiliar os alunos a serem cidadãos conscientes e consumidores responsáveis. Sendo assim;

Vivemos em uma sociedade de consumo repleta de mensagens, códigos, símbolos e signos publicitários, frente aos quais nos sentimos, muitas vezes, impotentes e desorientados. Para reverter tal situação, devemos começar a alfabetizar os alunos de forma audiovisual, bem como ensiná-los a ler criticamente a publicidade e a refletir sobre seus efeitos em nossos hábitos cotidianos de consumo, na formação das crianças e jovens e na estética da nossa cidade. (INMETRO, 2002, p.32)

Baseando-se na ideologia do consumo consciente, Cerbasi (2012) acredita que, conforme as pessoas aprendem a controlar sua vida financeira, consumindo de forma consciente, conseguem ter maior segurança, não somente em relação ao consumo, mas também em suas escolhas de investimentos. O autor complementa afirmando que quanto mais você exercita sua organização financeira, mais disciplinada será sua vida. 


\section{Metodologia}

Este trabalho foi desenvolvido na forma de uma pesquisa descritiva, buscando solucionar um determinado problema e as possíveis variáveis de solução. Conforme Silva (2003, p.64), "a pesquisa descritiva tem o objetivo de descrever as características de determinada população ou fenômeno, estabelecendo relações entre as variáveis".

O estudo foi realizado em uma escola da rede pública do município de Rio Grande - RS, onde os pesquisadores desenvolveram as atividades de extensão proposta no projeto, que aborda a educação financeira para jovens do ensino fundamental de escolas públicas.

As atividades do projeto foram desenvolvidas em três momentos. No primeiro, foi apresentado um vídeo da Bm\&fBovespa, contendo conteúdos sobre educação financeira, acessível à faixa etária do público-alvo, e realizado um jogo educativo, com o objetivo de aplicar os pontos apresentados no vídeo. Conforme Almeida, Castro e Cavalcanti (2014), a forma lúdica como os vídeos são apresentados possibilita aos alunos um melhor entendimento do assunto tratado, além de permitir uma melhor compreensão do que está sendo estudado.

No segundo momento, foi realizado o jogo "a trilha das compras", no qual os alunos puderam realizar compras ou não com a renda obtida e demonstrar seus conhecimentos financeiros. No terceiro momento, a coleta de dados ocorreu por meio de aplicação de um questionário, abordando a educação financeira dos alunos. De acordo com Oliveira (2003, p.71), "o questionário é uma das formas mais utilizadas para obtenção de dados, por permitir mensuração mais exata". Ele foi aplicado com o objetivo de identificar quais informações foram entendidas pelos estudantes com a atividade desenvolvida. Participaram desta pesquisa, 55 alunos, com idade entre 12 e 13 anos, do 6ํano da referida escola.

Os dados obtidos pelo questionário foram tratados por meio de uma análise quantitativa, usando a estatística descritiva, fundamentalmente, através de análises de percentuais das respostas das questões fechadas, e uma análise qualitativa da questão aberta. O questionário era composto por 8 (oito) questões fechadas e 1 (uma) aberta. 


\section{Percepção dos estudantes sobre a importância da educação financeira}

Conforme Kiyosaki e Lecheter (2000), a educação financeira deveria ser ensinada desde nossos primeiros anos de vida. Deveríamos ter noções sobre educação financeira desde a nossa infância, pensando que nem todos os pais possuem conhecimentos financeiros para educar seus filhos nesse campo. A escola deveria possuir disciplinas obrigatórias sobre finanças desde o ensino fundamental. No entanto, poucas são que as possuem, dificultando a solução desse problema tão grande enfrentado pelos jovens, como endividamentos pessoais, por falta de conhecimento.

Trevisan et al. (2007), em sua pesquisa, buscou identificar o interesse dos alunos em estudar na escola disciplinas sobre educação financeira e pôde perceber que os alunos demonstram interesse pelo tema. Para os alunos, a educação financeira pode auxiliá-los em seu dia a dia, podendo ajudá-los em questões pessoais, na hora de administrar seu orçamento, assim como na hora de realizar uma compra ou até mesmo obter um empréstimo.

Ainda em relação à educação financeira, Trevisan et al. (2007) expõem que os alunos, ao serem indagados sobre se existiria uma idade certa para aprender sobre finanças, cerca de $90 \%$ respondeu que não existiria uma idade mínima para começar a aprender sobre o assunto, e que, quanto antes começassem, melhor preparados estariam para o futuro. Apenas $10 \%$ dos alunos acreditam que ainda são imaturos para lidar com tal problemática, mostrando ainda uma dependência de seus pais nesse tema. Eles ainda pensam que as finanças são responsabilidade dos adultos, e que só devem se preocupar com esse tema quando chegarem nessa etapa da vida.

Na pesquisa de Grando e Schneider (2011), sobre a relação entre matemática e educação financeira, pode-se observar que os alunos também entendem como educação financeira a parte do conteúdo relativo à matemática financeira, relacionando-o com a prática de suas vidas em compras com desconto à vista, juros pagos em compras a prazo e empréstimos em bancos. Por exemplo, na hora de fazer uma compra à vista, saber quanto valem os descontos oferecidos pelos comerciantes; já em compras parceladas, saber o quanto está sendo cobrado de juros. $\mathrm{O}$ aluno ainda destaca que, como as prestações ficam menores, as pessoas, enganadas pela facilidade, não enxergam os juros que estão pagando nas compras 
parceladas.

Conforme estudo de Pereira e Zdanowicz (2015), alguns alunos, mesmo com pouca idade, já possuem cartão de crédito, conta bancária ou caderneta de poupança. Conforme o relato desses alunos, alguns acabam por gastar mais do que ganham em seu cartão de crédito e têm que pedir dinheiro emprestado à família. No entanto, há aqueles que, mesmo em minoria, já administram suas "mesadas" de forma correta, conseguindo até mesmo poupar um pouco. Cerca de $70 \%$ dos alunos entrevistados dizem receber informações sobre finanças por meio de seus pais, e apenas $15 \%$ deles obtêm essas informações na escola.

Correia (2015) relata que os alunos não se preocupam com seu comportamento consumista, estão focados apenas em uma formação profissional que os permita não depender de seus pais e com o fato de a sua renda ter capacidade de comprar tudo o que desejam. Mostram, assim, um despreparo para o mercado, dando continuidade ao consumismo alienado, uma problemática na vida financeira desses jovens.

No estudo realizado por Potrich, Vieira e Ceretta (2013), os autores observaram que mesmo estudantes de graduação não apresentam um nível satisfatório de educação financeira. Os resultados da pesquisa evidenciam que somente aqueles alunos que fazem curso de ciências contábeis, administração, economia e alguns cursos de engenharia possuem em seus currículos alguma disciplina sobre o assunto. Assim sendo, é possível que todo o restante dos alunos universitários não possua disciplina a respeito de educação financeira. No questionário proposto aos alunos, menos da metade dos entrevistados conseguiram responder corretamente as perguntas relacionadas a finanças pessoais.

Ainda em se tratando de disciplinas na graduação que auxiliam os alunos em informações sobre educação financeira, Vieira, Bataglia e Sereia (2011) afirmam que os alunos, ao responderem o questionário proposto, relatam, em sua maioria, que as informações financeiras que possuem vêm do âmbito familiar, o que demonstra novamente a falha nos currículos das universidades em formar um cidadão consciente, participativo e independente socialmente.

As tabelas de 1 a 5 apresentam os resultados, obtidos a partir dos dados coletados nesta pesquisa, relacionados à realidade dos alunos. Em seguida, nas tabelas 6 e 7, apresentam-se aqueles obtidos a partir da atividade proposta, ou seja, 
como os alunos se comportaram durante o jogo.

O questionário foi estruturado, buscando compreender o grau de entendimento que os alunos possuem sobre educação financeira, assim como seu comportamento na hora de realizar compras. A primeira questão apresentada aos alunos se refere à mesada, se eles ganham ou não, e o seu valor. As opções de resposta eram: até $R \$ 50,00$; entre $R \$ 50,00$ e $R \$ 100,00$; e quem ganha mais de $\mathrm{R} \$ 100,00$.

Tabela 1 - Média de valor das mesadas recebidas pelos estudantes

\begin{tabular}{|l|c|}
\hline Alternativas & Percentual de respostas \\
\hline Não ganham mesada & $50 \%$ \\
\hline Ganham até $R \$ 50,00$ & $34 \%$ \\
\hline Ganham entre $R \$ 50,00$ e $R \$ 100,00$ & $9 \%$ \\
\hline Ganham mais de $R \$ 100,00$ & $7 \%$ \\
\hline Fonte: elaborada pelos autores (2017) & \\
\hline
\end{tabular}

Com base na Tabela 1, foi possível constatar que $50 \%$ dos alunos entrevistados não ganham mesada, portanto, não costumam tomar decisões que envolvam atitudes financeiras, por não lidarem com o dinheiro diretamente. Borges (1999) afirma que a mesada pode ser um mecanismo de aprendizado de como as crianças podem lidar com seu dinheiro e adquirir produtos que caibam nesse valor, mostrando-lhes que não podem ter tudo de uma só vez e que, para possuir alguma coisa de maior valor, é necessário poupar o dinheiro.

A maioria dos alunos que recebem mesada (34\%) já vivencia situações financeiras, que os possibilitam tomar decisões em relação a suas finanças e assim se acostumarem a consumir de acordo com o que ganham. Os que ganham entre $R \$ 50,00$ e $R \$ 100,00$ somam $9 \%$, e os que ganham mais $R \$ 100,00$ somam $7 \%$. Embora esses recebam um valor maior, e, a princípio, deveriam poupar uma parte da sua mesada, são os alunos que mais gastam o dinheiro, sem nenhuma forma de controle. 
Tabela 2 - Forma de poupar o dinheiro

\begin{tabular}{|l|c|}
\hline Alternativas & Percentual de respostas \\
\hline Metade do valor ganho & $47 \%$ \\
\hline Uma pequena parte do valor & $33 \%$ \\
\hline Não poupa nada & $14 \%$ \\
\hline Não respondeu & $6 \%$ \\
\hline Fonte: elaborada pelos autores (2017) & \\
\hline
\end{tabular}

$\mathrm{Na}$ segunda questão, foi perguntado aos alunos se eles costumavam guardar alguma parte de seu dinheiro. Aqui, o que chamou a atenção foi que os alunos que ganhavam os valores mais altos em dinheiro, gastavam tudo, e alguns ainda relataram que pediam mais dinheiro a seus pais.

Com base nas respostas da Tabela 2, pode-se observar que parte desses alunos não possui nenhum tipo de preocupação com seu futuro, pois, por receberem uma quantidade maior de dinheiro, deveriam ter um controle maior sobre ele, visto que quanto mais ganham, mais estão gastando. Para Vieira, Bataglia e Sereia (2011), os alunos bem informados financeiramente, conseguirão planejar seus gastos e poupar seu dinheiro, de forma a manter o controle de suas finanças.

Tabela 3 - Elaboração de Planejamento e Participação no Planejamento do Orçamento Familiar

\begin{tabular}{|l|c|}
\hline Alternativas & Percentual de respostas \\
\hline Sim & $82 \%$ \\
\hline Não & $18 \%$ \\
\hline Você ajuda no planejamento do orçamento & \\
\hline Sim & $25 \%$ \\
\hline Não & $75 \%$ \\
\hline
\end{tabular}

Fonte: elaborada pelos autores (2017)

$\mathrm{Na}$ terceira questão, foi perguntado aos alunos se seus pais têm o costume de fazer o planejamento de sua renda mensalmente, e se eles participam de alguma forma nesse planejamento. Os alunos apresentaram grande dificuldade em responder a questão, pois a maioria não sabia o que era fazer o planejamento do orçamento. Teve-se que explicar, várias vezes, para mais da metade dos alunos. No caso dessa questão, não ficou clara a atuação dos alunos no planejamento, ou até mesmo se as famílias o realizam de fato.

Embora o resultado tenha sido que $82 \%$ realizam o planejamento, o que seria 
ótimo devido à necessidade de se planejar antes de gastar, não se pode embasar nessa perspectiva, pelo fato de os alunos responderem à pergunta de forma insegura, baseados nos conceitos que foram apresentados anteriormente a eles. Para Souza, Silva e Queiroz (2013), a falta de consciência e de informações sobre a importância do planejamento familiar financeiro vem mostrando resultados contrários aos esperados, como, por exemplo, o aumento do endividamento e, por consequência, a perda da qualidade de vida.

Para Cerbasi (2004), as crianças devem participar do planejamento familiar conforme sua idade, devido à grandeza dos números, que, para crianças muito pequenas, pode parecer muito dinheiro, mas, na realidade, pode ser uma quantia ainda insuficiente para o sustento da família.

Tabela 4 - Lugar onde recebem informações sobre finanças

\begin{tabular}{|l|c|}
\hline Alternativas & Percentual de respostas \\
\hline Com seus pais & $75 \%$ \\
\hline Na escola & $5 \%$ \\
\hline Com seus pais e na escola & $6 \%$ \\
\hline Na internet & $5 \%$ \\
\hline Com outros & $9 \%$ \\
\hline
\end{tabular}

Fonte: elaborada pelos autores (2017)

$\mathrm{Na}$ quarta questão, o foco era descobrir como os alunos recebem a maior parte de seus conhecimentos financeiros e buscar visualizar qual o meio que mais Ihes transmite esses conhecimentos.

$\mathrm{Na}$ Tabela 4, fica evidente que as crianças aprendem mais sobre educação financeira com seus pais do que em outros meios, tais como: Internet, escola, entre outros. De acordo com Souza, Silva e Queiroz (2013), uma grande parte da população é desprovida de conhecimentos financeiros; sendo assim, essas crianças, em sua maioria, estão aprendendo a lidar com seu dinheiro de forma distorcida, por falta de conhecimento relacionado a finanças. Portanto, deveria haver outros lugares em que pudessem buscar esses conhecimentos, para além do ambiente familiar.

Conforme Kiyosaki e Lacheter (2000), as escolas ensinam com maior ênfase as atividades profissionais, afastando-se da realidade e das necessidades que os alunos precisam para aprender sobre educação financeira. Dessa forma, não adianta terem um bom rendimento escolar, se estão sujeitos a conviverem com 
problemas financeiros por toda sua vida.

Tabela 5 - A importância de poupar dinheiro para o futuro

\begin{tabular}{|l|c|}
\hline Respostas & Percentual de respostas \\
\hline Poupar para ter dinheiro no futuro se precisar & $37 \%$ \\
\hline Poupar para ter dinheiro para coisas necessárias & $45 \%$ \\
\hline $\begin{array}{l}\text { Poupar para ter dinheiro para comprar coisas } \\
\text { desnecessárias }\end{array}$ & $18 \%$ \\
\hline
\end{tabular}

Fonte: elaborada pelos autores (2017)

$\mathrm{Na}$ questão 5 , procurou-se identificar se os alunos possuem ou não o hábito de poupar uma parte de seu dinheiro. A maioria disse que sim, que guarda seu dinheiro para eventuais necessidades futuras. É interessante destacar o que eles entendem por necessidade, pois as respostas foram bem diversas.

Para alguns, suas necessidades estão relacionadas à sua família, a comprar alimentos, comprar gás quando terminar, até comprar fraldas para o irmão menor. Para outro grupo de alunos, a necessidade está em guardar dinheiro para viagens, realizar compras em outras cidades. E, para outros, a necessidade seria comprar uma casa, ter um carro, guardar dinheiro para quando precisar.

Para Kiyosaki e Lechter (2000), os jovens encontram uma facilidade muito grande em possuir crédito, mesmo os que não possuem nenhuma informação de como lidar com o dinheiro, sendo totalmente analfabetos financeiros, fato que os torna despreparados para utilizar seus recursos de forma correta e para poupar para o futuro.

Tabela 6 - Distribuição dos gastos na atividade proposta

\begin{tabular}{|l|c|}
\hline Alternativas & Percentual de respostas \\
\hline Não gastou nenhum dinheiro & $29 \%$ \\
\hline Gastou a maior parte com alimentação & $36 \%$ \\
\hline Gastou a maior parte em vestuário & $1 \%$ \\
\hline Gastou a maior parte em outras coisas & $34 \%$ \\
\hline
\end{tabular}

A sexta questão trata de como os alunos organizaram seus gastos na hora em que estavam participando do jogo proposto; se gastaram a maior parte com alimentação, com vestuário, com outras coisas não importantes ou não gastaram dinheiro algum. 
Nessa questão, foi possível notar que o vídeo apresentado no primeiro momento da pesquisa teve alguma repercussão, pois a maioria dos alunos, a saber, $36 \%$, gastaram a maior parte com alimentação, pensando primeiro em suas necessidades mais básicas.

A Tabela 6 mostra que 34\% dos alunos gastaram a maior parte em outras coisas que não eram importantes, o que mostra uma diferença muito pequena de apenas $2 \%$ entre aqueles que compram de forma consciente e aqueles que compram por comprar, ou seja, consumidores imaturos. De acordo com Souza, Silva e Queiroz (2013), esses jovens serão futuramente responsáveis por seu lar e, se não tiverem habilidade econômica suficiente, terão dificuldades quando se depararem com essa situação. Deve-se observar que $29 \%$ dos alunos não gastou dinheiro algum, e que parte desses não utilizou o dinheiro, porque não surgiu a oportunidade de comprar o que desejavam, pois o jogo só possibilitava compras dos objetos em que o estudante chegava a cada movimento. Poucos foram os alunos que não compraram, a fim de guardar seu dinheiro para uma necessidade maior.

No entanto, muitos alunos responderam que costumam guardar uma grande parte de seu dinheiro, mostrando possuir alguma maturidade sobre educação financeira. Embora recebam valores menores de mesada, talvez por estarem acostumados com pouco dinheiro, poupam mais, o que, para seu futuro, será um hábito de grande valia.

Tabela 7 - Planejamento das compras no jogo

\begin{tabular}{|l|c|}
\hline Alternativas & Percentual de respostas \\
\hline Comprou o que mais gostou conforme a marca & $29 \%$ \\
\hline Comprou o mais barato & $47 \%$ \\
\hline Não se preocupou com o preço das compras & $9 \%$ \\
\hline Não respondeu & $15 \%$ \\
\hline Fonte: elaborada pelos autores (2017) & \\
\hline
\end{tabular}

A sétima questão está relacionada a como os alunos realizaram suas compras durante o jogo $A$ Trilha das Compras. Essa questão serviu para compreender como os alunos se organizaram para gastar seu dinheiro, se gastaram tudo, se escolheram produtos conforme os preços, por marcas ou se simplesmente realizaram compras até não sobrar dinheiro algum.

$\mathrm{Na}$ Tabela 7, é possível perceber o despreparo de alguns alunos em relação 
ao planejamento de seu orçamento. Mesmo com 47\% dos alunos comprando coisas mais baratas, o número de alunos que compram conforme a marca que gostam ou simplesmente compram sem se importar com o preço ainda foi muito grande. Percebe-se que falta informação sobre o que comprar e para que comprar. $O$ planejamento das compras deve ser realizado com antecedência, para que se possa ver o que sobrará de seu orçamento e se a compra não excederá o seu limite de renda.

Muitos alunos se preocuparam em poupar para comprar coisas de maior necessidade no futuro, mas $29 \%$ compraram conforme a marca dos produtos e $9 \%$ não se preocuparam com preço e o que representava pagar mais caro. Nessa linha, Cerbasi (2004) menciona que a mesada é uma forma de experiência que os filhos possuem para se relacionar com o dinheiro e que deve haver uma conversa entre pais e filhos, para que haja um planejamento dos gastos, visto que é preciso fazer escolhas ao comprar, pois não se pode comprar tudo o que se quer.

\section{Considerações finais}

O objetivo do presente trabalho foi descrever a percepção dos estudantes do ensino fundamental sobre a educação financeira e seu uso no planejamento do orçamento familiar, abordando as contribuições da educação financeira para um planejamento do orçamento de forma sustentável, em que se buscou verificar a participação dos jovens desde sua infância, para que se torne um adulto responsável financeiramente e, dessa forma, tenha uma melhor qualidade de vida.

Após a análise das questões, não foi possível perceber se realmente as famílias dos alunos possuem o hábito de planejar seu orçamento, pelo fato de eles responderem ao questionário com muitas dúvidas sobre a questão, mostrando que não estavam familiarizados com o assunto. São poucos os que participam junto a suas famílias na elaboração do planejamento do orçamento e demonstraram seu conhecimento por ele. É importante que os alunos participem diretamente dele, pois, assim, irão se familiarizando com o assunto e se preparando para, no futuro, saberem gerir suas finanças com responsabilidade.

Nesse sentido, observa-se a contribuição deste trabalho para alertar a comunidade sobre a necessidade de o jovem e a criança terem orientações sobre finanças desde novos, tanto na família como na escola, pois isso irá lhes 
proporcionar o desenvolvimento de habilidades para o futuro, principalmente, sob o foco, nesse caso, das finanças.

De forma mais direta, em se tratando de aquisição de habilidades financeiras, nota-se que os alunos não se encontram preparados para as tomadas de decisões necessárias para uma vida financeira controlada e segura, precisando adquirir informações sobre finanças, não somente do âmbito familiar, mas de outros ambientes que possam auxiliá-los de forma eficaz nas decisões. Ainda há poucas iniciativas por parte MEC para incluir no currículo escolar conceitos e informações financeiras aos alunos, salvo algumas exceções que se pôde conhecer durante a pesquisa.

Sob esse aspecto, é importante ressaltar que a escola é uma extensão do ambiente familiar, e o presente estudo indica que a maior parte dos estudantes obtém conhecimentos sobre finanças com seus pais, ou seja, a escola ainda tem pouca participação nessa formação. Considerando que muitos pais não têm instrução suficiente para ensinar sobre educação financeira da melhor forma, a escola poderia suprir esse conhecimento, formando estudantes que possam enfrentar a situação econômica do país com mais consistência, trazendo benefícios pessoais para o estudante e, de alguma forma contribuindo para a sociedade, a família e a realidade econômica e financeira do país.

As limitações do trabalho estão relacionadas ao grupo pesquisado, ou seja, uma turma do ensino fundamental. Sugere-se, em estudos futuros, ampliar o número de estudantes, bem como aplicar a atividade em séries e escolas diferentes, para poder comparar com os resultados obtidos no presente estudo.

\section{Referências bibliográficas}

ALMEIDA, Thamara Araújo; CASTRO, Caílon França de; CAVALCANTI, Eduardo Luiz Dias. A influência da linguagem audiovisual no ensino e na aprendizagem em aulas de química. Revista Tecnologias na Educação, v. 6, n. 11, p.11-27, 2014.

BARBOSA, Livia. Sociedade de consumo. 3ㄹa ed. Rio de Janeiro: Zahar, 2010. Disponível em:

<https://books.google.com.br/books?id=qPn_PcnZR88C\&pg=PA7\&hl=pt-

$B R \&$ source=gbs_toc_r\&cad=3\#v=onepage\&q $\& f=$ true $\geq$. Acesso: 24 abr. 2017.

BAUMAN, Zygmunt. Vida para consumo: a transformação das pessoas em mercadorias. Rio de Janeiro: Jorge Zahar, 2008. 
BORGES, Luísa. Salve seu bolso: o mais completo guia para antes, durante e depois da compra. São Paulo: Petrópolis, 1999.

BUSSINGER, Eliana. As leis do dinheiro para mulheres: como nossas mães nunca mais. Rio de Janeiro: Elsevier, 2005.

BRASIL. Ministério da Educação/ SEF. Referenciais para a formação de professores. Brasília, $2002 . \quad$ Disponível em: $<$ http://www.dominiopublico.gov.br/download/texto/me000511.pdf $\geq$. Acesso em: 30 mar. 2017.

BRASIL. Lei no 9.394, de 20 de dezembro de 1996. Estabelece as Diretrizes e Bases da Educação Nacional. Brasília, DF. 1996. Disponível em: <http://portal.mec.gov.br/seesp/arquivos/pdf/lei9394_ldbn1.pdf>. Acesso em: 30 abr. 2017.

BRAUNSTEIN, S.; WELCH, C. Financial literacy: an overview of practice, research, and policy. Federal Reserve Bulletin, p. 445-457, 2002.

CARVALHO, Nelly de. Publicidade: a linguagem da sedução. $3^{a}$ ed. São Paulo: Ática, 2000.

CERBASI, Gustavo. Casais inteligentes enriquecem juntos. São Paulo: Gente, 2004.

Como organizar sua vida financeira: inteligência pessoal na prática. Rio de Janeiro: Elsevier, 2012.

CORREIA, Fabiano Wernner de Souza. Educação Financeira. São Paulo, Universidade São Judas Tadeu São Paulo, 2015. Disponível em: <http://www.educacaofinanceira.com.br/tcc/fabianowernner.pdf>. Acesso em: 30 ago. 2016.

INMETRO, Instituto Nacional de Metrologia, Normalização e Qualidade Industrial. Publicidade e consumo - Coleção para o consumo responsável. Brasília: IDEC, Instituto Brasileiro de Defesa do Consumidor, 2002.

GRANDO, Neiva Ignês; SCHNEIDER, Ido José. Educação financeira; o que pensam alunos e professores. Revista Educação em Questão, v.40, n. 26, p.195-219, 2011.

KIYOSAKI, Robert T; LECHTER, Sharon L. Pai rico, pai pobre: o que os ricos ensinam a seus filhos sobre dinheiro. Rio de Janeiro: Elsevier, 2000.

LELLIS, Irani Lauer; MAGALHÃES, Celina Maria Colino; LEITE, Iani Dias Lauer. O significado da mesada para pais de crianças e adolescentes. Revista Interinstitucional de Psicologia, v.4, n.1, p.12-25, 2011.

MELLO, Guiomar Namo de. Formação inicial de professores para a educação básica: uma (re) visão radical. São Paulo em Perspectiva, v. 14, n. 1, p. 98-110, 2000.

OLIVEIRA, Benedito Silva. Métodos e técnicas de pesquisa em contabilidade. São Paulo: Saraiva, 2003.

PEREIRA, Elizete da Silva; ZDANOWICZ, José Eduardo. A educação financeira nas escolas de Santo Antônio da Patrulha - RS. Revista de Administração de Empresas Eletrônica, n.1, p.1-24, 2015. 
PETER, Luciani Dallmann; PALMEIRA, Eduardo Mauch. Estudo sobre a Inclusão da Educação Financeira como Disciplina Escolar a partir das Séries Iniciais. En Atlante. Cuadernos de Educación y Desarrollo, p.1-25, 2013. Disponível em:

<http://atlante.eumed.net/educacao-financeira/>. Acesso em: 30 out. 2016.

POTRICH, Ani Caroline Grigion; VIEIRA, Kelmara Mendes; CERETTA, Paulo Sergio. Nível de alfabetização financeira dos estudantes universitários: afinal o que é relevante? Revista Eletrônica de Ciência Administrativa (RECADM), v.12, n.3, p. 314-333, 2013.

SANTOMÉ, Jurjo Torres. Globalização e interdisciplinaridade: o currículo integrado. Porto Alegre: Artmed,1998.

SAVOIA, J. R. F.; SAITO, A. T.; SANTANA S. A. Paradigmas da educação financeira no Brasil. Revista de Administração Pública, v.41, n.6, p. 1121-1141, 2007.

Disponível em: <http://www.scielo.br/pdf/rap/v41n6/06.pdf> . Acesso em: 30 out. 2016.

SILVA, Ana Beatriz Barbosa. Mentes consumistas: do consumismo à propulsão por compras. São Paulo: Globo. 2014. Disponível em:

<http://lelivros.today/book/baixar-livro-mentes-consumistas-ana-beatriz-barbosasilva-em-pdf-epub-e-mobi/>. Acesso em: 20 dez. 2016.

SILVA, Antônio Carlos Ribeiro de. Metodologia de pesquisa aplicada à contabilidade: orientações de estudos, projetos, relatórios, monografias, dissertações, teses. São Paulo: Atlas, 2003.

SOUZA, Ronie Cléber de et al. A importância da educação financeira no contexto atual: a realidade dos bairros Riacho do Meio e Manuel Deodato em Pau dos FerrosRN. Revista Extendere, p. 180-194, 2013.

VIEIRA, Saulo Fabiano Amâncio; BATAGLIA, Regiane Tardiolle Manfre; SEREIA, Vanderlei José. Educação financeira e decisões de consumo, investimentos e poupança: uma análise dos alunos de uma universidade pública do norte do Paraná. Revista de Administração da UNIMEP, v.9, n.3, p. 61-86, 2011. 